\title{
Azygos anterior cerebral artery aneurysm with subarachnoid hemorrhage
}

\author{
Dhiman Chowdhury, Nazmin Ahmed, Bipin Chaurasia, Kanak Kanti Barua \\ Department of Neurosurgery, Bangabandhu Sheikh Mujib Medical University, Dhaka 1000, Bangladesh. \\ Correspondence to: Dr. Bipin Chaurasia, Department of Neurosurgery, Bangabandhu Sheikh Mujib Medical University, Dhaka 1000, \\ Bangladesh. E-mail: trozexa@gmail.com
}

How to cite this article: Chowdhury D, Ahmed N, Chaurasia B, Barua KK. Azygos anterior cerebral artery aneurysm with
subarachnoid hemorrhage. Neuroimmuno/ Neuroinflammation 2018;5:39. http://dx.doi.org/10.20517/2347-8659.2018.37

Received: 8 Jun 2018 First Decision: 10 Aug 2018 Revised: 10 Aug 2018 Accepted: 13 Aug 2018 Published: 28 Sep 2018

Science Editor: Athanassios P. Kyritsis Copy Editor: Yuan-Li Wang Production Editor: Zhong-Yu Guo

Azygos anterior cerebral artery (ACA) is type I variation of ACA with a reported incidence of $<1 \%$ in population ${ }^{[1]}$. This variation predisposes to the formation of aneurysm especially at the bifurcation zone. The aneurysm develops because of double hemodynamic pressure supplying medial surface of both cerebral hemispheres.

However reported incidence of saccular aneurysm in azygos ACA is between $13 \%$ and $71 \%{ }^{[2,3]}$. It is often associated with other central nervous system (CNS) malformations like agenesis of corpus callosum, hydranencephaly and other vascular malformations ${ }^{[4]}$.

In this paper we report a patient who presented with subarachnoid hemorrhage. Later on we did three dimensional (3D) computed tomography (CT) image. She was then diagnosed as a case of azygos ACA aneurysm.

A 50-year-old female presented with a history of sudden onset of severe headache followed by transient loss of consciousness. There was no previous history of hypertension and diabetes mellitus. During admission she had mild dull aching headache and neck rigidity. There was no focal neurological deficit (Hunt and Hess grade-I).

Four hours after the incident, CT scan of brain revealed subarachnoid hemorrhage in the basal cistern and hematoma in the interhemispheric fissure [Figure 1] which was Fisher CT scan grade 3. After 7 days of the incident repeat CT scan of brain was done which showed diminution of the size of hematoma [Figure 2]. At

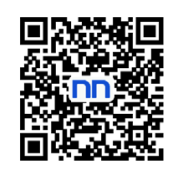




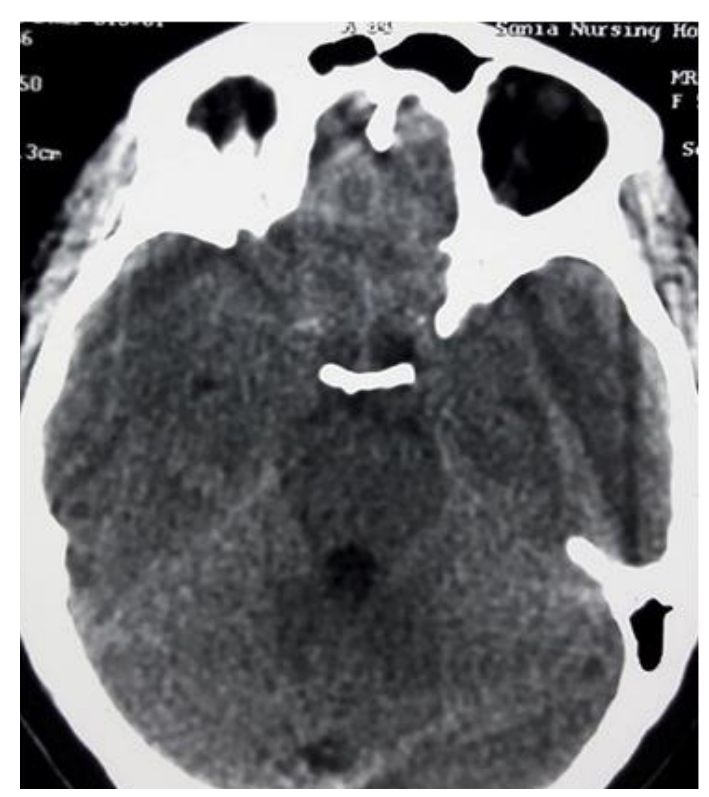

Figure 1. CT scan of brain shows subarachnoid hemorrhage and hematoma in the interhemispheric fissure. CT: computed tomography

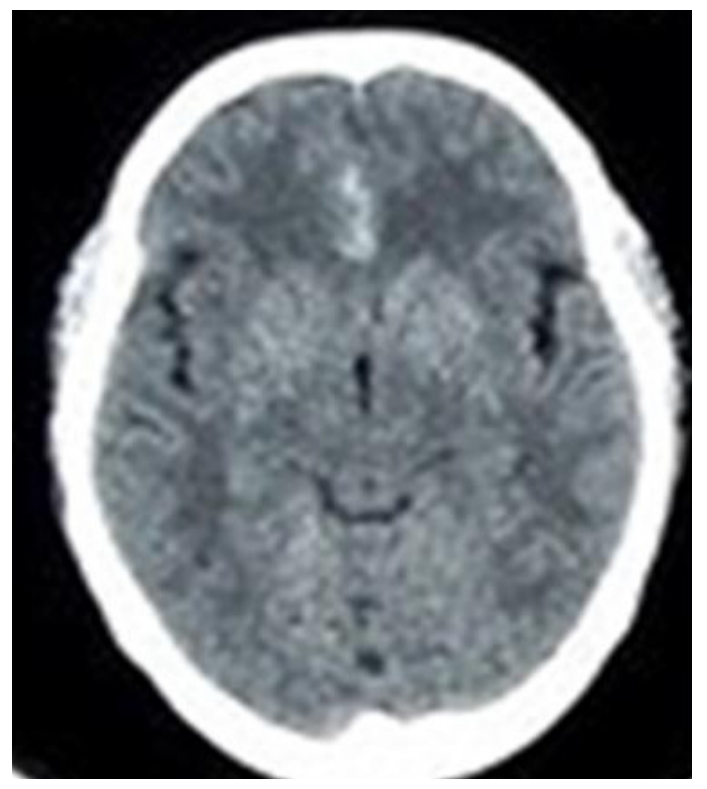

Figure 2. After 7 days, CT scan of brain shows diminution of the size of hematoma. CT: computed tomography

that time, a 3D CT angiogram revealed single saccular aneurysm from the bifurcation zone of azygos ACA [Figure $3 \mathrm{~A}$ and $\mathrm{B}$ ].

The patient underwent right paramedian frontal craniotomy and clipping of the aneurysm through anterior interhemispheric approach. After application of temporary clip on unpaired A2 segment, dissection of aneurysm neck was done and a curved fenestrated titanium clip was applied keeping the callosomarginal artery within the fenestration. There was no peroperative rupture of the aneurysm during dissection of aneurysm neck and fundus. Post-operative periods were uneventful.

Two months after the surgery, we did 3D CT angiogram which showed the patency of the vessels and the 

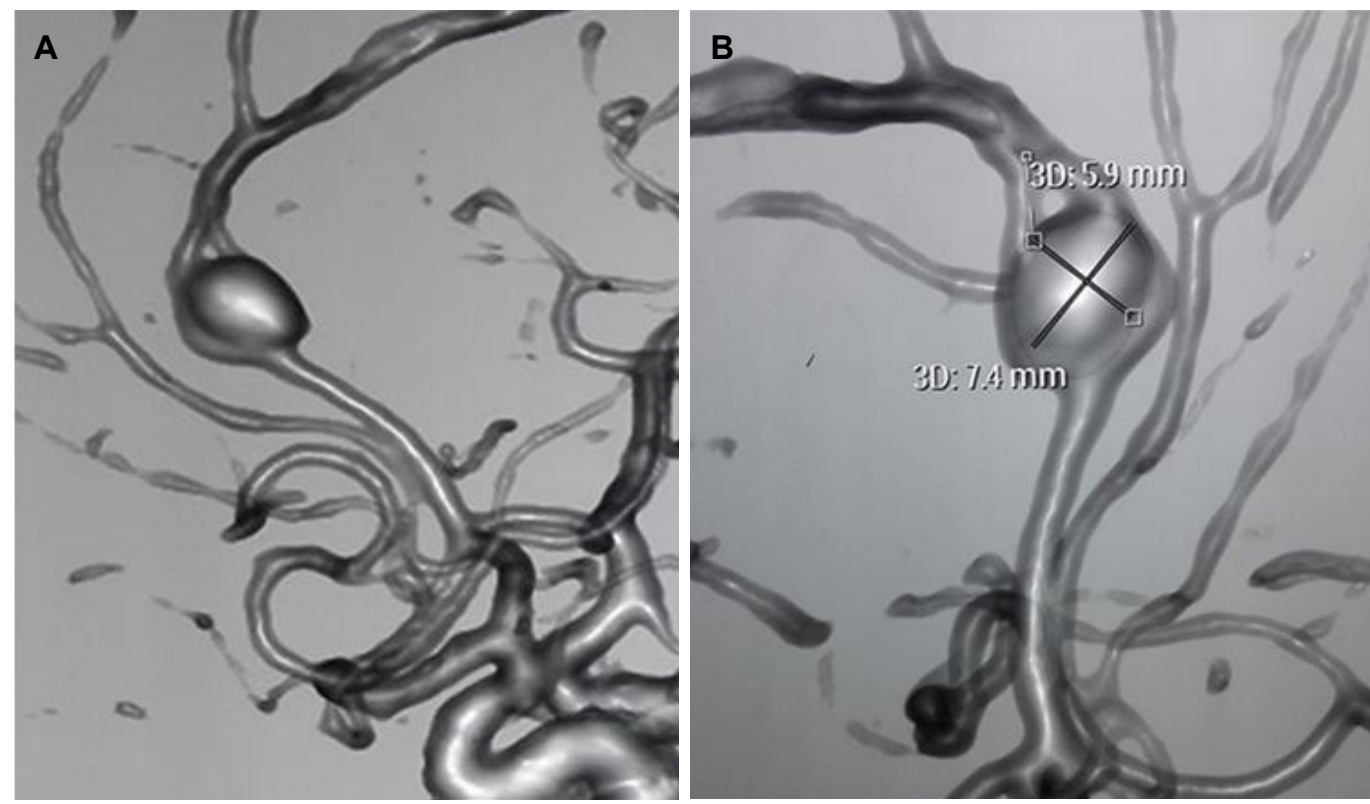

Figure 3. (A) 3D CT angiogram demonstrating a saccular aneurysm arising from the bifurcation zone of azygos $A C A$; (B) $3 D$ CT angiogram showing a 5.9 by $7.4 \mathrm{~mm}$ saccular aneurysm. 3D: three dimensional; CT: computed tomography
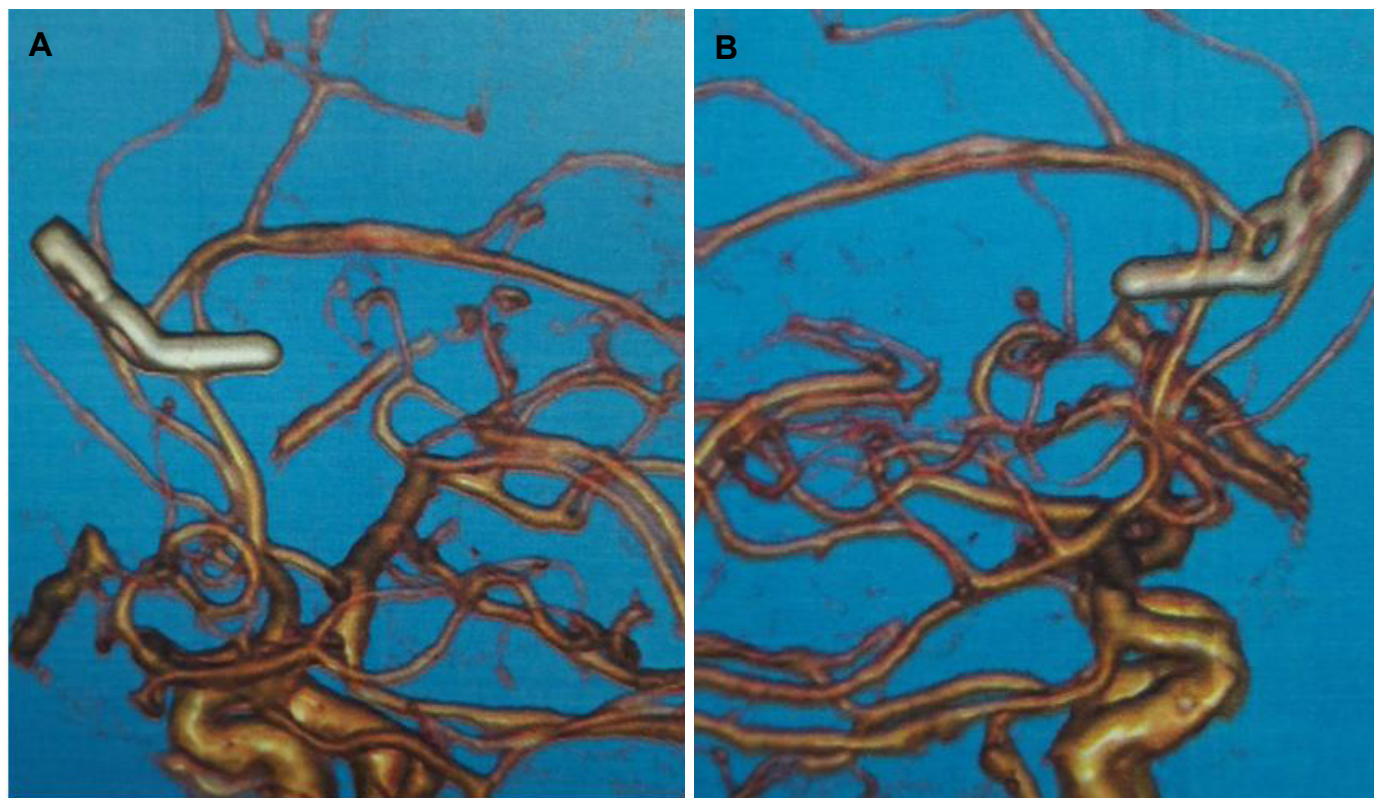

Figure 4. (A and B) Post-operative 3D CT angiogram demonstrating complete obliteration of the aneurysm. 3D: three dimensional; $C T$ : computed tomography

complete obliteration of the aneurysm [Figure $4 \mathrm{~A}$ and $\mathrm{B}$ ].

According to Baptista ${ }^{[7]}$, there are three variations of ACA [Figure 5]. Type 1 anomaly [Figure 5A] denotes azygos ACA from which all major vessels arise and supply both hemispheres. In type II variation [Figure $5 \mathrm{~B}$ ] both right and left A2 present and major branches supplying both hemispheres arises from dominant A2. Type III anomaly [Figure $5 \mathrm{C}$ and $\mathrm{D}$ ] denotes accessory ACA arising from anterior communicating artery. In our case, the surgery was done on the basis of $3 \mathrm{D}$ CT angiogram findings and azygos nature of ACA was confirmed preoperatively. 
A

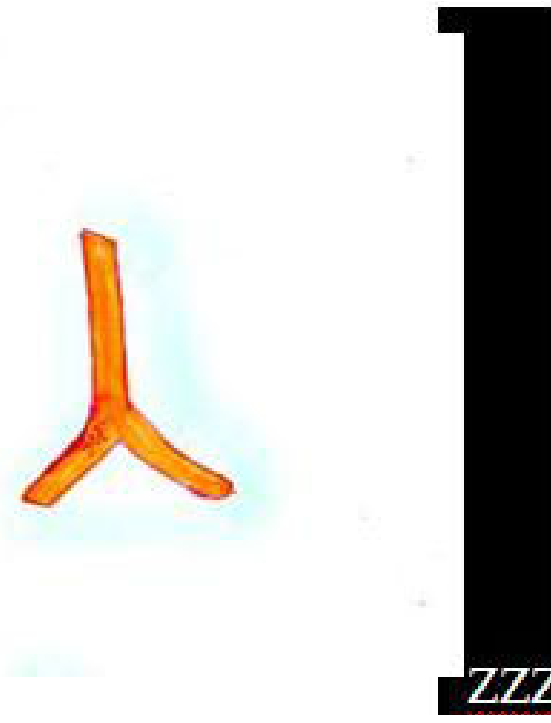

C

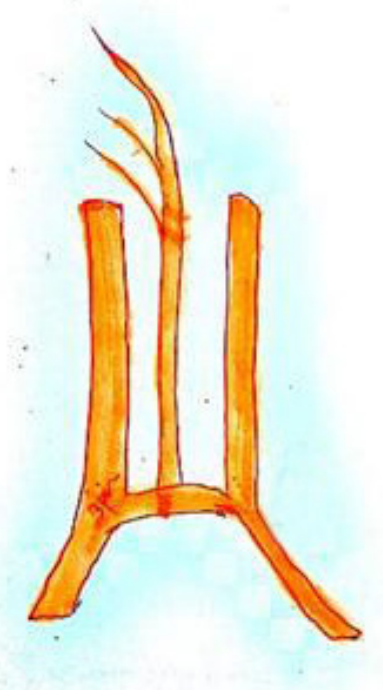

B

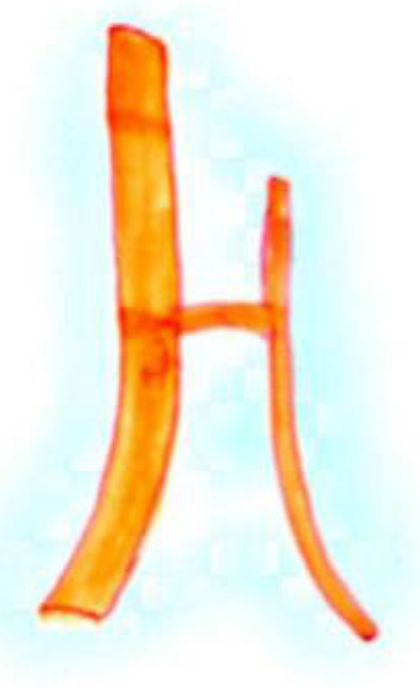

D

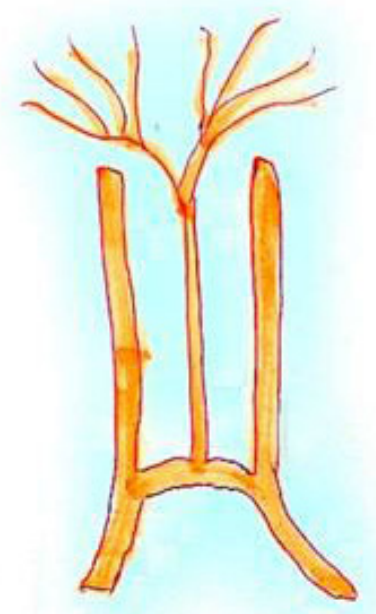

Figure 5. (A) Azygos ACA in which single ACA feeds into medial surface of both cerebral hemisphere. ACA: anterior cerebral artery; (B) Bihemispheric ACA, in which two ACA, one is dominant with branches extending into contralateral hemisphere; (C and D) Accessory ACA in which a median artery supply either one or both hemispheres. ACA: anterior cerebral artery

Though reported incidence of azygos ACA is $<1 \%{ }^{[1]}$, Ghanta et al. ${ }^{[6]}$ reported that $25 \%$ cases of distal anterior cerebral artery (DACA) aneurysms were associated with azygos ACA. Katz et al. ${ }^{[7]}$ found 17\% ACA aneurysm among 36 DACA aneurysm cases. The nature of the aneurysm was mostly saccular. Although saccular bilobed aneurysm of ACA was also reported by Jagetia et al. ${ }^{[8]}$.

Both surgical clipping and endovascular coiling can be done to manage azygos ACA aneurysm. In our case, temporary clip was applied for $5 \mathrm{~min}$ in proximal unpaired A2 segment. Then a dissection of the aneurysm neck was done and finally a permanent clip was applied. There was no neurological deficit in her postoperative period.

In conclusion, we can say that azygos aneurysm can be clipped well without any postoperative morbidity and mortality. Though we tried to manage this case in an emergency basis, we failed due to the patient's poor financial condition. 


\section{DECLARATIONS}

Authors' contributions

Design: Chowdhury D

Literature research, manuscript editing: Chaurasia B

Data analysis, manuscript writing: Ahmed N

Manuscript revision: Chowdhury D, Barua KK

\section{Availability of data and materials}

Not applicable.

\section{Financial support and sponsorship}

None.

\section{Conflicts of interest}

All authors declared that there are no conflicts of interest.

\section{Ethical approval and consent to participate}

Not applicable.

\section{Consent for publication}

Not applicable.

\section{Copyright}

(c) The Author(s) 2018.

\section{REFERENCES}

1. Ozkal E, Erongun U, Acar O, Kalkan E. Ruptured aneurysm of an azygous anterior cerebral artery. Turk Neurosurg 1990;1:140-2.

2. Niizuma H, Kwak R, Uchida K. Suzuki J. Aneurysms of the azygos anterior cerebral artery. Surg Neurol 1981;15:225-8.

3. Huh JS, Park SK, Skin JJ. Kim TH. Saccular aneurysms of the azygos anterior cerebral artery: three case reports. J Korean Neurosurg Soc 2009;42:342-5.

4. Binatli Ö, Özer FD, Aydin M, Çiçek E, Binatli YC. Azygos anterior cerebral artery aneurysm with concomittant vascular anomaly: case report. World J Neuroscience 2013;3:49.

5. Baptista AG. Studies on the arteries of the brain. II. The anterior cerebral artery: some anatomic features and their clinical implications. Neurology 1963;13:825-35.

6. Ghanta RK, Kesanakurthy MV, Vemuri VN. Aneurysm of azygos anterior cerebral artery: a report of two cases. Asian J Neurosurg 2016;11:312.

7. Katz RW, Horoupian DS, Zingesser L. Aneurysm of azygous anterior cerebral artery. A case report. J Neurosurg 1978;48:804-8.

8. Jagetia A, Kumar PN, Sinha S, Sharma A. Saccular bilobed aneurysm of an azygos anterior cerebral artery. J Clin Neurosci 2007;14:777-9. 